\title{
COR, BETACAROTENO E COLESTEROL EM GEMA DE OVOS OBTIDOS DE POEDEIRAS QUE RECEBERAM DIFERENTES DIETAS
}

\author{
Color, beta-caroten and cholesterol in yolks of eggs by different diets of laying hens
}

\author{
Luciana Marino e Biscaro ${ }^{1}$, Solange Guidolin Canniatti-Brazaca²
}

\begin{abstract}
RESUMO
O ovo é um alimento considerado nutricionalmente completo, e contém quantidade significativa de nutrientes. Para os consumidores, a qualidade deste alimento está relacionada com o prazo de validade do produto e com as características sensoriais, como cor da gema e da casca. Poucos estudos foram efetuados no Brasil sobre a utilização de agentes pigmentantes e seus efeitos sobre a coloração das gemas e proporção e qualidade química dos componentes do ovo. Com base nisso, objetivou-se com este trabalho relacionar diferentes dietas com cor, quantidade de betacaroteno e teor colesterol das gemas dos ovos. Foram coletados ovos de poedeiras que receberam 4 diferentes tipos de ração. A cor foi medida em colorímetro Minolta, o beta-caroteno separado em coluna e medido em espectrofotômetro e o colesterol extraído com clorofórmio e quantificado por método colorimétrico. Os resultados mostraram que não há relação entre a cor e aumento do teor de betacaroteno das gemas dos ovos, mas a alimentação alterou a cor da gema. O teor de colesterol foi diferente $(\mathrm{p} \leq 0,05)$ para os tratamentos 1 e 3 . Portanto, os diferentes tipos de alimentação das poedeiras testados influenciaram na cor, mas não tiveram relação com beta-caroteno. O colesterol das gemas sofreu alteração com os diferentes tipos de alimentação.
\end{abstract}

Termos para indexação: Ovo, ração, coloração, caroteno, galinha.

\begin{abstract}
Egg is a nutritional complete food, and content significant quantity of nutrients. For the consumers, the food quality is related with validity date of product and with sensorial characteristics, like yolk color and hull. Few studies were done in Brazil about utilization of colorfull agents and theirs effects in yolk color and chemical quality of egg compounds. The objective of this research was related different feeds with the color, beta-carotene and cholesterol amount of egg yolk. Eggs were caught of laying hens that received 4 feed types. The color measure was done by Minolta colorimeter, beta-carotene separated by column and spectrophotometer and cholesterol separated with chloroform and measured by colorimetric method. The results showed that there is not a relation between the color an increase of beta-carotene amount in the yolks, but feed altered the yolk color. Cholesterol amount was different $(\mathrm{p} \leq 0,05)$ between treatments 1 and 3 . The different feeds of laying hens altered color, but it did not relate with beta-carotene. The cholesterol in the yolk altered too.
\end{abstract}

Index terms: Egg, feed, coloration, carotene, chicken.

(Recebido para publicação em 3 de abril de 2006 e aprovado em 11 de julho de 2006)

\section{INTRODUÇÃO}

Segundo dados do IBGE (2005), a quantidade de ovos produzidos no Brasil é alta. Em junho de 2004, a produção de ovos de galinha foi de 157.937 dúzias, sendo também de baixo custo, com média de $\mathrm{R} \$ 37,64 / \mathrm{Kg}$, no mês de maio de 2005 (AVISITE, 2005). Por apresentar preços acessíveis, o ovo é muito consumido pela população brasileira, fazendo parte do seu hábito alimentar (RODRIGUES \& SALAY, 2001). O ovo é um alimento nutricionalmente completo. Dentre seus componentes está a vitamina $\mathrm{A}$, que pode ser pré ou pós-formada.

O betacaroteno é o que possui maior atividade de provitamina A entre os carotenóides (RODRIGUEZAMAYA, 1985) e também antioxidante (BRASIL, 2005; MINAZZI-RODRIGUES \& PENTEADO, 1989).
Os carotenóides influenciam na cor da gema. A intensidade de sua coloração é um critério de decisão em relação à preferência do consumidor, pois normalmente associa-se a pigmentação da gema a sua quantidade de vitaminas (OLIVEIRA, 1996). Segundo Oliveira (1996), poucos estudos foram efetuados no Brasil sobre a utilização de agentes pigmentantes e seus efeitos sobre a coloração das gemas e proporção e qualidade química dos componentes do ovo.

A pigmentação resulta da deposição de xantofilas (grupo de pigmentos carotenóides) na gema do ovo. As fontes de pigmentos carotenóides podem ser naturais, como, por exemplo, as do grupo do milho e do pimentão vermelho, entre outros. Podem ser empregados também carotenóides sintéticos, tais como a cantaxantina 10\% (pigmento vermelho) e o etil éster beta apo-8-caroteno (pigmento amarelo) (GARCIA et al., 2002).

\footnotetext{
${ }^{1}$ Graduanda em Ciências dos Alimentos - Escola Superior de Agricultura Luiz de Queiroz/ Universidade de São Paulo - Cx. P. 9 - 13.418-900 Piracicaba, SP - lucimb@esalq.usp.br

${ }^{2}$ Professor Doutor do Departamento de Agroindústria, Alimentos e Nutrição - Escola Superior de Agricultura Luiz de Queiroz - Universidade de São Paulo Cx. P. 9 - 13.418-900 - Piracicaba, SP - sgcbraza@esalq.usp.br
} 
Garcia et al. (2002) avaliaram os efeitos de diferentes níveis de inclusão de um agente pigmentante, cantaxantina a $10 \%$, sobre a qualidade dos ovos e o desempenho de poedeiras comerciais. Com base nos resultados encontrados, puderam concluir que a inclusão de cantaxantina na dieta não influenciou os parâmetros produtivos e de qualidade dos ovos, exceto a coloração das gemas. $\mathrm{O}$ melhor resultado foi obtido com a adição de 60 ppm de cantaxantina aos 5,43 dias de inclusão do pigmentante à dieta, sendo atingindo a cor plateau de 14,3 do leque colorimétrico Roche.

De acordo com Krsmanovic (1980), dietas para poedeiras com citraxantina como carotenóide sintético resultaram em ovos com gema de coloração significativamente mais forte quando comparados ao grupo controle, sem adição de agente pigmentante como suplemento. O mesmo autor constatou que o efeito dos carotenóides sintéticos foi maior quando as aves foram alimentadas com dietas contendo pequenas quantidades de pigmentos provenientes de fontes naturais.

Schoner et al. (1990), comparando a eficiência da cantanxantina $10 \%$ e citraxantina $10 \%$, constataram que ambos os carotenóides sintéticos incorporados às dietas de poedeiras tornaram a coloração dos ovos estáveis durante 12 semanas de armazenamento em temperatura de sala de estocagem.

Silva et al. (2002) demonstraram que a adição de $0,1 \%$ do extrato de urucum às rações de poedeiras contendo $40 \%$ de sorgo resulta em pigmentação da gema dos ovos similar à obtida com rações contendo milho como fonte de energia.

Devido à importância do ovo e o efeito da alimentação na composição do ovo, a pesquisa teve por objetivo relacionar a alimentação da galinha com a cor, quantidade de betacaroteno, colesterol das gemas dos ovos.

\section{MATERIAIS E MÉTODOS}

Os ovos foram coletados em produtores da região, obtendo todas as informações necessárias para a comparação entre as diferentes amostras, sendo que cada produtor forneceu diferentes rações às aves poedeiras (com ou sem substâncias promotoras de cor, em diferentes níveis). Foram coletados 24 ovos de cada tratamento e imediatamente realizadas as análises de cor e teor de betacaroteno e colesterol nas amostras. Na tabela 1, mostram-se os diferentes tratamentos analisados.

\section{Medida de cor}

Foi utilizado colorímetro Minolta CR-200 b, previamente calibrado em superfície branca de acordo com padrões pré-estabelecidos segundo Bible \& Singha (1993) e Mutschler et al. (1992).

Foram avaliados 3 valores do croma: $a^{*}, b^{*}$ e L. O valor de $a^{*}$ caracteriza coloração na região do vermelho $\left(+\mathrm{a}^{*}\right)$ ao verde $\left(-\mathrm{a}^{*}\right)$, o valor $\mathrm{b}^{*}$ indica coloração no intervalo do amarelo $\left(+b^{*}\right)$ ao azul ( $\left.-b^{*}\right)$. O valor $\mathrm{L}$ nos fornece a luminosidade, variando do branco $(\mathrm{L}=100)$ ao preto $(\mathrm{L}=0)$.

\section{Colesterol}

A separação de lipídios da gema foi realizada de acordo com o método de Folch et al. (1957). Foi pesada um grama de amostra em Becker e foram adicionados 20 gramas da mistura clorofórmio : metanol, 2:1. A mistura foi filtrada em papel filtro número 1 e o filtrado foi colocado em funil

TABELA 1 - Tratamentos - diferentes alimentações ( $\mathrm{kg}$ de componente em $1000 \mathrm{~kg}$ de ração).

\begin{tabular}{ccccc}
\hline Componente (kg/100 kg) & Tratamento 1 & Tratamento 2 & Tratamento 3 & Tratamento 4 \\
\hline Fubá de milho & 658,7 & 613 & 658,6 & 550 \\
Farelo de soja & 181 & 221 & 189 & $330^{5}$ \\
Farelo de trigo & 12 & 23 & 15 & 15,2 \\
Farinha de carne & 47,7 & 51 & 39 & - \\
Calcário & 93,8 & 86 & 90,4 & $100^{5}$ \\
Sal & 2,8 & 3 & 3 & 3 \\
Suplemento $^{1}$ & $4^{2}$ & $3^{3}$ & $5^{4}$ & $1,8^{6}$ \\
\hline
\end{tabular}

${ }^{1}$ Suplemento vitamínico, mineral e aminoácido para aves; ${ }^{2}$ Nucleomix Egg-P4; $;{ }^{3}$ Premix $;{ }^{4}$ Premix + cloreto de colina + metionina em pó + polimin aves; ${ }^{5}$ Farelo de soja + óleo de soja; ${ }^{6}$ Calcário + Fosfato bicálcico; ${ }^{7}$ Pó de pimentão. 
de separação. Foi acrescentado $50 \mathrm{ml}$ de água destilada adicionada de $0,02 \%$ de cloreto de cálcio. Foram lavadas 5 vezes com a mistura clorofórmio:metanol:água, nas proporções (8:4:3), utilizando $100 \mathrm{ml}$ por lavagem.

O colesterol da gema dos ovos foi determinado quantitativamente, por método colorimétrico, proposto por Bohac et al. (1988).

\section{Betacaroteno}

O betacaroteno foi determinado segundo método proposto por Minazzi-Rodrigues \& Penteado (1989). Cinco gramas de material e $50 \mathrm{ml}$ de acetona foram homogeneizados em liquidificador, marca Skymseneletro modelo LI, por aproximadamente 5 minutos, e posteriormente colocado em refrigerador por 20 minutos. A mistura obtida foi filtrada em papel filtro número 1 e o resíduo lavado com $25 \mathrm{ml}$ de éter de petróleo. As lavagens foram adicionadas ao extrato e colocado em funil de separação para a separação da fase hexano (carotenóides), da fase da água e acetona, que foram descartadas. A lavagem foi repetida para remoção total da acetona com mais 4 porções de $100 \mathrm{ml}$ de água, sendo obtido o extrato em hexano.

Para a separação dos pigmentos, o extrato foi aplicado em coluna com magnésia ativada sob vácuo. A coluna foi lavada com $50 \mathrm{ml}$ de acetona: hexano 1:9. O volume do eluído foi medido em proveta e realizada leitura em espectrofotômetro a $436 \mathrm{~nm}$.

\section{Delineamento Estatístico}

Inteiramente ao acaso com aplicação do teste $\mathrm{F}$, e quando significativo, teste de Tukey (5\%). Foi utilizado o software estatístico SAS Institute (1998).

\section{RESULTADOS E DISCUSSÃO}

Os resultados encontrados para a cor das gemas são apresentados na Tabela 2.

$\mathrm{Na}$ amostra 4 temos a adição de pimentão vermelho para a pigmentação das gemas, que irá propiciar a deposição de xantofilas (GARCIA et al., 2002). Nos demais grupos temos o milho somente.

As rações formuladas para poedeiras comerciais contêm o milho amarelo como principal fonte de energia e de pigmentos naturais, como xantofilas, que contribuem para produção de gema de coloração alaranjada. Entretanto, em caso da utilização de sorgo, mandioca, farelo de arroz, milheto, algaroba e adlai, em algumas regiões do País, o produtor pode substituir o milho parcial ou totalmente, em função da necessidade de redução dos custos de produção, o que traz como consequiência ovos com gemas mais claras que desagradam ao consumidor. Desta forma teremos gemas com diferentes tonalidades influenciadas pelos diferentes tipos de alimentação, como apresentado na Tabela 2. Esta coloração mais clara pode desagradar ao consumidor.

Hamilton (1992), trabalhando com pimentão, verificou que o carotenóide dietético (capsantina) foi depositado com eficiência de $16 \%$. Para o tratamento 4 que recebeu adição de pó de pimentão pode ser observado que houve alteração significativa $(\mathrm{p} \leq 0,05)$ para $\mathrm{a}^{*}$, mesmo tendo a maior quantidade de soja adicionada à ração. Um componente natural intensifica o efeito o pigmentante artificial (KRSMANOVIC, 1980).

Quando comparados os valores obtidos na colorimetria (Tabela 2), observamos grande diferença apenas nos valores de $\mathrm{a}^{*}$, que representa coloração no intervalo do vermelho $\left(+\mathrm{a}^{*}\right)$ ao verde $\left(-\mathrm{a}^{*}\right)$. Portanto, os

TABELA 2 - Valores de L, a* e b* para medida de cor da gema de ovos que foram obtidos de poedeiras que receberam diferentes rações.

\begin{tabular}{cccc}
\hline \multicolumn{4}{c}{ Colorimetria } \\
\hline Tratamento & L & $\mathbf{a}^{*}$ & $\mathbf{B}^{*}$ \\
\hline 1 & $68,95 \pm 2,2^{1}$ & $-0,48 \pm 0,4^{\mathrm{b} 2}$ & $55,18 \pm 1,1$ \\
2 & $64,50 \pm 1,6$ & $-1,33 \pm 0,5^{\mathrm{bc}}$ & $53,83 \pm 2,3$ \\
3 & $67,30 \pm 2,7$ & $-2,40 \pm 0,9^{\mathrm{c}}$ & $54,63 \pm 1,8$ \\
$4^{\text {Valor F }}$ & $64,78 \pm 2,6$ & $4,10 \pm 0,8^{\mathrm{a}}$ & $52,43 \pm 7,3$ \\
\hline
\end{tabular}

${ }^{1}$ Média \pm desvio padrão.

${ }^{2}$ Médias seguidas de letras diferentes nas colunas, diferem entre si pelo teste de Tukey, em nível de significância de $5 \%(\mathrm{p} \leq 0,05)$.

Ciênc. agrotec., Lavras, v. 30, n. 6, p. 1130-1134, nov./dez., 2006 
ovos derivados de poedeiras que se alimentaram com ração adicionada de pó de pimentão (tratamento 4) obtiveram os melhores resultados, já que seus valores de $a^{*}$ ficaram mais elevados. O valor do tratamento 4 foi similar ao resultado encontrado por Harder (2005) quando adicionou $0,5 \%$ de urucum na ração de poedeiras.

TABELA 3 - Valor de $\beta$-caroteno em gema de ovos que foram obtidos de poedeiras que receberam diferentes rações.

\begin{tabular}{cc}
\hline Tratamento & $\boldsymbol{\beta}$ - caroteno $(\mathbf{m g} / \mathbf{1 0 0 g}$ de gema $)$ \\
\hline 1 & $8,01 \pm 0,1^{\mathrm{b} 2}$ \\
2 & $12,26 \pm 0,4^{\mathrm{a}}$ \\
3 & $6,40 \pm 0,2^{\mathrm{b}}$ \\
4 & $7,66 \pm 1,4^{\mathrm{b}}$ \\
Valor F & $35,10^{*}$ \\
\hline
\end{tabular}

${ }^{1}$ Média \pm desvio padrão.

${ }^{2}$ Médias seguidas de letras diferentes nas colunas, diferem entre si pelo teste de Tukey, em nível de significância de $5 \%(\mathrm{p} \leq 0,05)$.

Os valores encontrados para betacaroteno (Tabela 3) foram superiores aos encontrados por Harder (2005), que apresentou valores que variaram de 3,20 a 3,46 $\mu \mathrm{g} / \mathrm{g}$ de gema.

Quanto ao teor de b-caroteno, o maior valor encontrado foi no tratamento 2 , indicando que a adição do pó de pimentão, não tem relação com esse nutriente, assim como foi encontrado para o urucum (HARDER, 2005).

Atualmente, a intensidade da coloração da gema de ovos de galinha é muito importante na decisão de compra do consumidor, pois este geralmente associa a cor a valores nutricionais, principalmente o teor vitaminas, porém pelos resultados encontrados a cor não está relacionada ao aumento da quantidade de betacaroteno como observado quando comparados os resultados das Tabelas 2 e 3.

O teor de colesterol (Tabela 4) foi maior no tratamento 1 do que para o tratamento $3(\mathrm{p} \leq 0,05)$, indicando que o teor foi influenciado pela composição da dieta, porém não pela adição de agentes naturais promotores da cor da gema (pó de pimentão), como contatado por Harder (2005) utilizando urucum. Harder (2005) encontrou teor de colesterol de 10,41 a 16,95 mg/g de gema para ovos obtidos com adição de urucum, sendo que a adição de urucum diminuiu o teor do mesmo.
TABELA 4 - Teor de colesterol (mg/100 g) em gema de ovos que foram obtidos de poedeiras que receberam diferentes rações.

\begin{tabular}{cc}
\hline Tratamento & Colesterol $(\mathbf{m g} / \mathbf{1 0 0 g}$ de gema) \\
\hline 1 & $1288,6 \pm 72,9^{\mathrm{a}}$ \\
2 & $1194,4 \pm 303,4^{\mathrm{ab}}$ \\
3 & $860,1 \pm 62,3^{\mathrm{b}}$ \\
4 & $1086,9 \pm 25,2^{\mathrm{ab}}$ \\
Valor F & $40,1^{*}$ \\
\hline
\end{tabular}

${ }^{1}$ Média \pm desvio padrão.

${ }^{2}$ Médias seguidas de letras diferentes nas colunas, diferem entre si pelo teste de Tukey, em nível de significância de $5 \%(\mathrm{p} \leq 0,05)$.

\section{CONCLUSÕES}

Pelos resultados obtidos, pode-se concluir que a alimentação das galinhas poedeiras interferiu em todos os fatores avaliados (cor, beta-caroteno e colesterol). A alteração de cor não está relacionada com o aumento de betacaroteno.

\section{AGRADECIMENTOS}

Dr. Valter Arthur e a técnica Clarice Matraia do laboratório de irradiação de alimentos e radioentomologia CENA/USP, pela leitura de cor das amostras.

\section{REFERÊNCIAS BIBLIOGRÁFICAS}

AVISITE. Cotação diária do ovo. Disponível em: Www. avisite.com.br/economia/cotaovo.asp?. Acesso em: 20 jun. 2005.

BIBLE, B. B.; SINGHA, S. Canopy position influences cielab coordinates of peach color. Hortscience, Alexandria, v. 28, n. 10, p. 992-993, 1993.

BOHAC, C. E.; RHEE, K. S.; CROSS, H. R.; ONO, K. Assessment of methodologies for colorimetric cholesterol assay of meats. Journal of Food Science, Chicago, v. 53, n. 6, p. 1642-1644, 1988.

BRASIL. Ministério da Saúde. Área técnica de alimentação e nutrição. Disponível em <www.saude.gov.br $/ \mathrm{sp} \mathrm{s}_{1}$ !areastecnicas/carencias/index/hthl>. Acesso em: 15 jun. 2005.

FOLCH, J.; LEES, M.; STANLEY, G. H. S. A simple method for the isolation and purification of total lipides from animal tissues. Journal of Biological Chemistry, Baltimore, v. 226, p. 497-509, 1957. 
GARCIA, E. A.; MENDES, A. A.; PIZZOLANTE, C. C.; GONÇALVES, H. C.; OLIVEIRA, R. P.; SILVA, M. A. Efeitos dos níveis de cantaxantina na dieta sobre o desempenho e qualidade dos ovos de poedeiras comerciais. Revista Brasileira de Ciência Avícola, Campinas, v. 4, n. 1, jan./ abr. 2002. Disponível en: $<$ http://www.scielo.brit scielo.php>. Acesso em: 10 mar. 2006.

HAMILTON, P. B. The use of light-performance liquid cromatography for studying pigmentation. Poultry Science, Champaign, v. 71, p. 718-724, 1992.

HARDER, M. N. C. Efeito do urucum (Bixa orellana) na alteração de características de ovos de galinhas poedeiras. 2005. 74 f. Dissertação (Mestrado em Ciência e Tecnologia de Alimentos) - Escola Superior de Agricultura "Luiz de Queiroz”, Universidade de São Paulo, Piracicaba, 2005.

INSTITUTO BRASILEIRO DE GEOGRAFIA E ESTATÍSTICA. Banco de dados agregados. Disponível em: LWWw.ibge.govor/home/estatistica/indicador, agropecuaria/produccao agropecuarial abate02t200404.shtm>. Acesso em: 15 jun. 2005.

KRSMANOVIC, M. Coloring of egg yolk with synthetic carotenoids. Veterinária - Yuguslávia, [S.1.], v. 29, p. 216-23, 1980.

MINAZZI-RODRIGUES, R. S.; PENTEADO, M. de V. C. Carotenóides com atividade pró-vitamínica A em hortaliças folhosas. Revista de Farmácia e Bioquímica da Universidade de São Paulo, São Paulo, v. 25, n. 1, p. 39-52, jan./jun. 1989.
MUTSCHLER, M. A.; WOLFE, D. W.; COBB, E. D.; YOURSTONE, K. S. Tomato fruit-qulity and shelf-life in hybrids heterozygous for the alc ripening mutant. Hortscience, Alexandria, v. 27, n. 4, p. 352-355, 1992.

OLIVEIRA, B. L. Caderno técnico da Escola de Veterinária. Belo Horizonte: UFMG, 1996.

RODRIGUES, K. R. M.; SALAY, E. Atitudes de granjeiros, atacadistas, varejistas e consumidores em relação à qualidade sanitária do ovo de galinha in natura. Revista de Nutrição, Campinas, v. 14, n. 3, p. 185-193, set./dez. 2001.

RODRIGUEZ-AMAYA, D. B. Os carotenóides como precursores de vitamina A. Boletim da Sociedade Brasileira de Ciência e Tecnologia de Alimentos, Campinas, v. 19, n. 4, p. 227-242, out./dez. 1985.

SAS INSTITUTE. SAS user's guide: statistic. Version 6. 12. ed. Cary, 1998. $846 \mathrm{p}$.

SCHONER, F. J.; HOPPE, P. P.; WIESCHE, H. Feeding trials on laying hens with a newly developed carotenoid. Muhle Mischfuttertecnik, [S.1.], v. 127, p. 487-489, 1990.

SILVA, J. H. V.; ALBINO, L. F. T.; GODÓI, M. J. de S. Efeito do extrato de urucum na pigmentação das gemas dos ovos. Revista Brasileira de Zootecnia, Viçosa, v. 29, n. 5, set./ out. 2002. Disponível em: <http://www.scielo.bri scielo.php>. Acesso em: 10 mar. 2006. 